\section{$\underset{\text { hommes }}{\text { \& migrations }}$}

\section{Hommes \& migrations}

Revue française de référence sur les dynamiques

migratoires

1306 | 2014

Ecriture et migration

\title{
Guy Scarpetta, Guido
}

Paris, Gallimard, 2014, 407 pages, 23,50€.

\section{Mustapha Harzoune}

\section{(2) OpenEdition}

1 Journals

\section{Édition électronique}

URL : http://journals.openedition.org/hommesmigrations/2830

DOI : 10.4000/hommesmigrations.2830

ISSN : 2262-3353

\section{Éditeur}

Musée national de l'histoire de l'immigration

\section{Édition imprimée}

Date de publication : 1 avril 2014

Pagination : 121-122

ISBN : 978-2-919040-27-8

ISSN : $1142-852 X$

Référence électronique

Mustapha Harzoune, «Guy Scarpetta, Guido », Hommes \& migrations [En ligne], 1306 | 2014, mis en ligne le 06 août 2014, consulté le 22 septembre 2020. URL : http://journals.openedition.org/ hommesmigrations/2830; DOI : https://doi.org/10.4000/hommesmigrations.2830

Ce document a été généré automatiquement le 22 septembre 2020.

Tous droits réservés 


\section{Guy Scarpetta, Guido}

Paris, Gallimard, 2014, 407 pages, 23,50€.

\section{Mustapha Harzoune}

\section{RÉFÉRENCE}

Guy Scarpetta, Guido,

Paris, Gallimard, 2014, 407 pages, 23,50€.

\section{NOTE DE L'ÉDITEUR}

Sélection 2014 de la $5^{\mathrm{e}}$ édition du prix littéraire de la Porte Dorée

1 Guido est un texte ambitieux, inclassable. À la fois roman, fiction "raisonnée", témoignage, geste familiale et histoire nationale, document, confidence, récit historique, tragédie et épopée... Un arc-en-ciel littéraire qui se déploie tout du long sans pâlir, porté par une force d'expression et de conviction impressionnante. Quel que soit le registre, Guy Scarpetta est tout d'une pièce : intègre, sensible, fin, intransigeant, implacable, précis, limpide. Il offre, dans une langue somptueuse et une construction sans faiblesse, un récit sur la transmission et la mémoire, loin des petits devoirs d'estrade. Guy Scarpetta parle davantage du présent que du passé, s'adresse bien plus aux vivants qu'aux morts.

2 Guy Scarpetta raconte l'histoire de son grand-père, Guido, immigré italien, antifasciste et communiste, résistant, arrêté par la police française, interné et déporté avec plus de sept cents autres "triangles rouges" ou prisonniers politiques, dans ce "Train Fantôme", l'un des derniers convois en partance pour Dachau, dont la progression est freinée par les actions des résistants qui libèrent le pays. "La Tragédie fait irruption dans l'Épopée", écrit l'auteur. Le convoi est ralenti, détourné, stoppé parfois. Les prisonniers, affamés et épuisés, seront même contraints de marcher, pendant dix-sept kilomètres, sous la brûlure du soleil estival de Provence, jusqu'à la gare de Sorgues. Plus d'une fois 
cette tragédie aurait pu être évitée. La mort aurait pu épargner ces hommes et ces femmes. Rien n'y fit, le convoi poursuivit sa funeste marche vers les ténèbres, s'extrayant à chaque fois de cet halo de lumière qui gagnait le pays tout entier.

3 Avec Guido, La Divine Comédie de son compatriote Dante en poche, défile une partie de l'histoire de l'immigration en France, de l'immigration dans la Résistance. Ces hommes et ces femmes, ces métèques "au fond étaient la France, alors même que la plupart des Français de souche se soumettaient à l'occupant. J'ai su cela, très tôt. Et c'est sans doute de cela que je tiens cette méfiance radicale envers ceux dont la conception du monde se ramène au culte des racines. 'La terre ne ment pas', en ces années-là, c'était un slogan de Vichy. La liberté, elle, n'avait pas de patrie."

L'auteur - et cela aussi fait du bien - à contre-courant d'une certaine doxa, “n'aime pas beaucoup l'expression frelatée de 'devoir de mémoire', qui me semble, au fond, à peine moins rébarbative que celle de 'devoir conjugal'... La mémoire vivante, c'est tout autre chose. C'est ce qui passe par une transmission ouverte, éveillée, là où l'on ne s'inscrit pas dans une tradition pour s'y enfermer, mais pour sans cesse la relancer, la raviver, la réinventer, la faire respirer".

5 La mémoire ici est un souffle, un souffle vital qui se nomme "esprit de résistance". "Cet esprit qui est sans doute plus que jamais d'actualité, dans un monde où un inquiétant renouveau du fascisme se manifeste en Europe, de la Flandre à la Hongrie, et dont nous aurions tort de nous croire épargnés. Dans un monde où les injustices s'accroissent, et où les solidarités s'affaiblissent."

6 Cet esprit, éloigné des civilités de robot, des compassions mémorielles et des mines de circonstance, insuffle à chaque page le désir et la joie de vivre: “Guido n'est certainement pas mort pour nous plonger dans l'angoisse et la paralysie d'un deuil infini, mais qu'au contraire que triomphent, face aux forces de la mort programmée, de la barbarie, celles de la vie, de la joie, de la création, de la liberté épanouie. Tous ceux qui l'entouraient s'étaient aussi battus pour ce qu'ils nommaient 'un monde meilleur' pas pour qu'on les pleurent." 